\title{
Involvement of mitochondria in the assimilatory metabolism of anaerobic Saccharomyces cerevisiae cultures
}

\author{
Wiebe Visser, ${ }^{1} \dagger$ Adriaan A. van der Baan, ${ }^{1} \ddagger$ Wilma Batenburg-van der \\ Vegte, ${ }^{1}$ W. Alexander Scheffers, ${ }^{1}$ Reinhard $\mathrm{Krämer}^{2}$ and \\ Johannes P. van Dijken ${ }^{1}$
}

Author for correspondence: Johannes P. van Dijken. Tel: +31 15 782412. Fax: +3115782355.

\begin{abstract}
1 Department of Microbiology and Enzymology, Kluyver Laboratory of Biotechnology, Delft University of Technology, Julianalaan 67,2628 BC Delft, The Netherlands

2 Institut für Biotechnologie 1, Forschungszentrum Jülich GmbH, PO Box 1913 , D-52425 Jülich, Germany
\end{abstract}

\begin{abstract}
The possible physiological role of mitochondria in anaerobically grown Saccharomyces cerevisiae was investigated via enzyme localization and inhibitor studies. Almost all of the activity of citrate synthase (EC 4.1.3.7) was recovered in the mitochondrial fraction after differential centrifugation of spheroplast lysates. The enzyme exhibited a high degree of latency which was demonstrated by sonication of the mitochondrial fractions. Since citrate synthase is an important enzyme in anabolic reactions, a consequence of this localization is the requirement for transport of metabolites across the mitochondrial membranes. Such transport is likely to require energy which, as a result of anaerobiosis, cannot be supplied by respiration. It was therefore investigated whether ATP translocation into the mitochondria by an ADPIATP translocase might be involved in anaerobic mitochondrial energy metabolism. It was shown that addition of the ADPIATP translocase inhibitor bongkrekic acid to anaerobic cultures indeed inhibited growth, although only partially. It is concluded that mitochondria of $S$. cerevisiae fulfil a vital role in anaerobic sugar metabolism.
\end{abstract}

Keywords: Saccharomyces cerevisiae, (pro)-mitochondria, ADP/ATP-translocator, anaerobic continuous culture, citrate synthase

\section{INTRODUCTION}

The existence of mitochondria in anaerobically grown yeast cells has been disputed for a long period in the literature. Early reports (Wallace \& Linnane, 1964; Linnane, 1965; Chapman \& Bartley, 1968) claim that such cells are completely devoid of mitochondria and that adaptation to aerobic conditions involves de novo synthesis of these organelles. These reports were based on electron microscopic studies. Later it was shown that inadequate staining or fractionation procedures had led to these conclusions (Damsky et al., 1969; Cartledge et al., 1972; Cartledge \& Lloyd, 1972, 1973; Jenkins et al., 1984). Since the membranous structures found under anaerobic conditions were quite different from the well-known aerobic mitochondria, the term 'pro-mitochondria' was proposed to emphasize the relationship to aerobic organ-

\footnotetext{
†Present address: Nutricia, PO Box 1, 2700 MA, Zoetermeer, The Netherlands.

$\ddagger$ Present address: Bird Engineering, PO Box 149, 3100 AC Schiedam, The
} Netherlands. elles, as well as the differences between these organelles and fully functional mitochondria.

In all reports on the disappearance of mitochondria under anaerobic conditions, a discussion of the physiological consequences was restricted to the respiratory system, i.e. cytochromes and oxidases and the $\mathrm{F}_{1}$-ATPase (Groot $e t$ al., 1971). However, it is well-established that most enzymes of the citric acid cycle as well as some enzymes for sterol biosynthesis (Shimizu et al., 1973) and amino acid synthesis (Ryan \& Kohlhaw, 1974; Jauniaux et al., 1978) are localized inside the mitochondria and hence disappearance of the organelle could be lethal during growth under anaerobic conditions. Evidence for the indispensability of mitochondria is the fact that yeast proteins mediating protein import into mitochondria are essential for cell viability (Jensen \& Yaffe, 1988; Baker \& Schatz, 1991; Stuart et al., 1994).

Studies on the localization of mitochondrial enzymes under anaerobic conditions are complicated due to the very fragile structure of these mitochondria (Criddle \& Schatz, 1969; Damsky et al., 1969). Hence, in this study, 
great attention has been given to the isolation of intact mitochondria. Citrate synthase activity was taken as a marker enzyme in view of its key role in the TCA-cycle and since earlier reports showed that its activity under anaerobic conditions was not found in a particulate fraction (Wales et al., 1980). Under anaerobic conditions, all ATP is produced in the cytoplasm during glycolysis. If pro-mitochondria also fulfil a role in biosynthesis of cell material during anaerobic growth, energy must be supplied to the organelle both for driving transport processes across its membranes and for the energy-demanding reactions within (Groot $e t$ al., 1971). Import of ATP into mitochondria may occur via an ADP/ATP translocator in exchange for ADP. The possible physiological function of yeast mitochondria under strictly anaerobic conditions was therefore also studied by testing the sensitivity of anaerobic cells to bongkrekic acid, a well-known inhibitor of the ADP/ATP translocator.

\section{METHODS}

Micro-organism. Saccharomyces cerevisiae CBS 8066 was obtained from the Centraalbureau voor Schimmelcultures (Delft, The Netherlands) and maintained on malt agar slopes.

Media. Mineral medium, supplemented with vitamins and trace: elements, was prepared according to Verduyn et al. (1992). Glucose was added as sole source of carbon and energy, to a concentration of $30 \mathrm{~g} \mathrm{l}^{-1}$ unless stated otherwise. Ergosterol and Tween 80, supplements required for anaerobic growth of $S$. cerevisiae (Andreasen \& Stier, 1953, 1954) were dissolved in pure ethanol and sterilized by heating the solution for $10 \mathrm{~min}$ at $100{ }^{\circ} \mathrm{C}$. These components were added to the medium to a concentration of $6 \mathrm{mg} \mathrm{l}^{-1}$ and $660 \mathrm{mg} \mathrm{l}^{-1}$, respectively. To prevent foaming, $50 \mu \mathrm{l}$ silicone antifoam $\mathrm{l}^{-1}$ was added to the reservoir medium.

Growth conditions. The yeast was grown in continuous cultures, using a 2 litre laboratory fermenter of the type described by Harder $e$ t al. (1974), with a 1 litre working volume. The $\mathrm{pH}$ was controlled at 5.0 by automatic titration of $1 \mathrm{M}$ $\mathrm{KOH}$. The stirrer speed was maintained at 1000 r.p.m. and the cells were grown at $30^{\circ} \mathrm{C}$ at a dilution rate of $0 \cdot 1 \mathrm{~h}^{-1}$ unless stated otherwise.

To maintain anaerobic conditions, the fermenter was flushed with 1 litre $\min ^{-1}$ pure nitrogen gas, containing less than 5 p.p.m. oxygen (obtained from Air Products). To minimize diffusion of oxygen, Norprene tubing (Cole-Parmer Instruments) was used. Since dissolved oxygen in the growth medium will significantly contribute to the overall influx of traces of oxygen, the medium was stripped of oxygen using a second fermenter in which it was vigorously flushed with the nitrogen. From this fermenter the medium was pumped directly into the fermentation vessel. The outlet gas passed a cooled condenser $\left(4^{\circ} \mathrm{C}\right)$ and was subsequently led through a glycerol trap to prevent back diffusion of oxygen into the fermenter.

The dissolved-oxygen tension was measured continuously with an autoclavable polarographic (Clark type) oxygen electrode, type Ingold $322756702 / 74247$, connected to an Ingold $\mathrm{O}_{2}$ amplifier type 170 . As a result of the precautions mentioned above, the actual dissolved oxygen tension in the anaerobic cultures was below $0.005 \%$ air saturation.

For comparative purposes, cells were also grown aerobically in chemostat cultures. All parameters were kept the same, but the nitrogen gas was replaced with air and the glucose concentration in the reservoir was reduced to $5 \mathrm{~g}^{-1}$.
Analytical methods. Dry weight was determined by filtration of culture samples over weighed polysulfone filters (pore size $0.45 \mu \mathrm{m}$, Gelman Sciences). The filter was washed with demineralized water, dried in a microwave (Sharp) for $20 \mathrm{~min}$ at medium power and re-weighed.

Cultures were routinely analysed for metabolites. Organic acids were determined by HPLC on a HPX- $87 \mathrm{H}$ column $(300 \times$ $7.8 \mathrm{~mm}$, Bio-Rad) at $30^{\circ} \mathrm{C}$. The column was eluted with $0.005 \mathrm{M}$ $\mathrm{H}_{2} \mathrm{SO}_{4}$ at a flow rate of $0.6 \mathrm{ml} \mathrm{min}{ }^{-1}$. The detector was a Waters $441 \mathrm{UV}$-meter at $210 \mathrm{~nm}$, which was coupled to a Waters 741 data module. Glycerol and ethanol were also measured using this column by the use of a refraction index detector which was coupled in line with the UV detector.

Isolation of mitochondria from anaerobic cells. For the isolation of mitochondria, the procedure of Bruinenberg et al. (1985) was adopted. To prevent adaptation to aerobic conditions, all buffers and reagents were made anaerobic by flushing with argon and all incubations were carried out under an atmosphere of this gas. When the entrance of oxygen could not be avoided the samples were kept at $0{ }^{\circ} \mathrm{C}$ to prevent adaptation to aerobic conditions. Zymolyase $\left[1000 \mathrm{U}\right.$ (g cells) $\left.{ }^{-1}\right]$ was used for spheroplasting. During incubation small samples were taken and diluted 200-fold in water. The osmotic shock caused lysis of the spheroplasts, as determined by measuring $\mathrm{OD}_{660}$ of the solution. Incubation was stopped when the OD was $10 \%$ of the starting value. A crude mitochondrial fraction was obtained from the spheroplast lysates via differential centrifugation as described by Bruinenberg et al. (1985). The mitochondrial fractions were stabilized by the addition of $1 \mathrm{mg}$ bovine serum albumin (BSA) $\mathrm{ml}^{-1}$. The fractions $\mathrm{P} 1$ and $\mathrm{P} 2$ were obtained after centrifugation in an SS34 rotor of a Sorvall RC5B at 10000 r.p.m. at $10 \mathrm{~min}$ and 20000 r.p.m. at $20 \mathrm{~min}$, respectively.

When appropriate, the fractions were disrupted by ultrasonic treatment at $4{ }^{\circ} \mathrm{C}$ by the use of an MSE sonicator. Full power treatment $(30 \mathrm{~s}$, unless indicated otherwise, at $150 \mathrm{~W})$ was alternated with equal periods of cooling in ice-water.

Respiration measurements. Respiration measurements on cells and mitochondria were performed with a polarographic oxygen electrode (Clark type) in a stirred vessel at $30^{\circ} \mathrm{C}$ (Biological Oxygen Monitor). Cells were diluted in mineral medium without glucose. After determination of the endogenous respiration glucose was added to a final concentration of $20 \mathrm{mM}$. The oxygen uptake rate in the presence of glucose was taken as maximum respiratory capacity of the cells. Activity is expressed as $\mu \mathrm{mol} \mathrm{O} \mathrm{O}_{2} \mathrm{~min}^{-1}$ (g cell protein) ${ }^{-1}$ and based on a protein content of whole cells of $47 \%$ (Verduyn et al., 1990).

Oxygen consumption of mitochondria was measured in $25 \mathrm{mM}$ potassium phosphate buffer $(\mathrm{pH} 7 \cdot 0$ ) containing $5 \mathrm{mM} \mathrm{MgCl}$, $0.65 \mathrm{M}$ sorbitol and $0.17 \mathrm{mM}$ ADP using $0.25 \mathrm{mM} \mathrm{NADH}$ as substrate. To verify whether the oxygen consumption by whole cells and isolated mitochondria was mediated by cytochrome oxidase, activity was tested by adding cyanide to the solution to a final concentration of $1 \mathrm{mM}$.

Enzyme assays. Glucose-6-phosphate dehydrogenase (EC 1.1.1.49) was assayed according to Bruinenberg et al. (1983). The activity of NADH dehydrogenase (EC 1.6.99.3) was determined as described by Bruinenberg et al. (1985). Citrate synthase was assayed in a $100 \mathrm{mM}$ Tris/ $\mathrm{HCl}$ buffer $(\mathrm{pH} \mathrm{8.0)}$ containing $\quad 0.10 \mathrm{mM} \quad 5,5^{\prime}$-dithiobis(2-nitrobenzoic acid) (DTNB) and $0.05 \mathrm{mM}$ acetyl CoA. After addition of the sample, the reaction was started with oxaloacetate (final concentration $0.25 \mathrm{mM}$ ). The appearance of coenzyme $A$ was followed spectrophotometrically at $412 \mathrm{~nm}\left(\varepsilon=13.6 \mathrm{mM}^{-1} \mathrm{~cm}^{-1}\right)$. Protein determinations in mitochondrial fractions were disturbed by the addition of BSA and therefore not performed. 

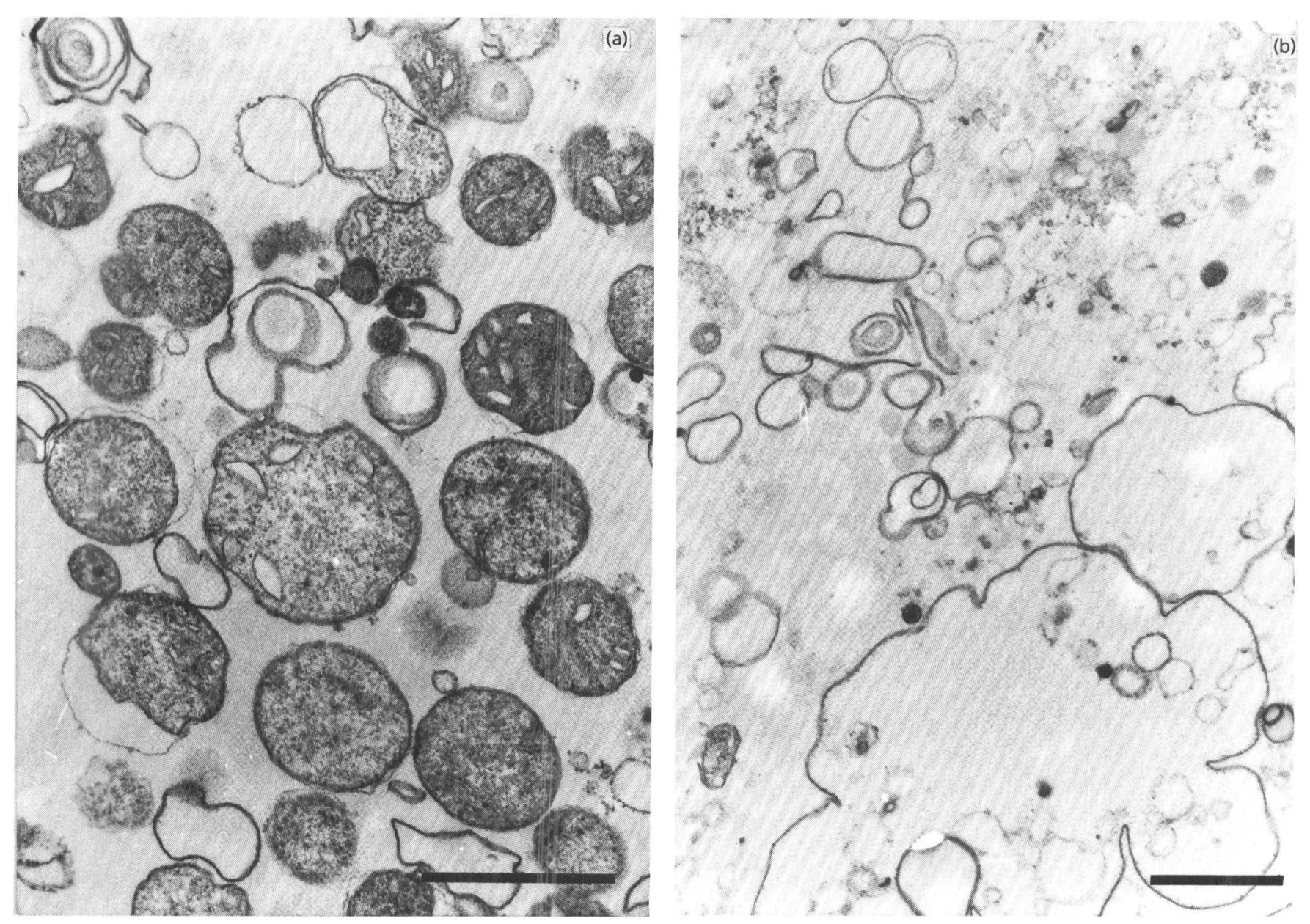

Fig. 1. Electron micrographs of subcellular fractions from anaerobically grown, glucose-limited $S$. cerevisiae cells (bars, $1 \mu \mathrm{m})$. Cells were grown at a dilution rate of $0 \cdot 10 \mathrm{~h}^{-1}$. (a) P1-fraction, mainly containing pro-mitochondria. (b) P2-fraction, mainly containing membranes and vesicles.

Chemicals. Tween 80 was obtained from Merck. Zymolyase $(100000 \mathrm{~T})$ was purchased from the Kirin brewery, Japan. Antifoam was obtained from $\mathrm{BDH}$. Bongkrekic acid was a gift of Professor J. A. Duine from our department.

\section{RESULTS}

\section{Isolation of mitochondria}

S. cerevisiae cells were grown under strictly anaerobic conditions and glucose limitation at a dilution rate of $0 \cdot 1 \mathrm{~h}^{-1}$. The procedure for the isolation of pro-mitochondria was based on the method of Bruinenberg $e t$ al. (1985) and van Urk et al. (1989), developed for the isolation of mitochondria from aerobically grown cells of Candida utilis and $S$. cerevisiae, respectively. The essentials of these procedures are enzymic degradation of the cell wall with Zymolyase in hypertonic medium, followed by dialy'sis of the spheroplast suspension to lower its osmotic value gently. Spheroplasts are then mechanically disrupted by a few strokes in a Potter-Elvejhem homogenizer. Mitochondrial fractions are subsequently isolated by differential centrifugation. These fractions were named $\mathrm{P} 1, \mathrm{P} 2$ and $\mathrm{S}$ according to earlier experiments (Wales $e$ t al.,
1980; Bruinenberg et al., 1985; van Urk et al., 1989). The P1 fraction contains mostly mitochondria, the P2 fraction contains the remaining membranes and the $\mathrm{S}$ fraction is the final supernatant or soluble fraction.

In the method of van Urk et al. (1989), pretreatment of the aerobically grown cells with DTT and EDTA was necessary to obtain spheroplasts at a satisfactory rate. DTT, however, interfered with our measurements of citrate synthase activity due to remaining residues after washing. These traces of DTT reacted with the DTNB used in the citrate synthase assay. Further checking showed that pretreatment of cells with DTT, EDTA or the combination of the two did not enhance the rate of spheroplasting of anaerobically grown $S$. cerevisiae with Zymolyase and hence this pretreatment was omitted from the procedure.

When pro-mitochondria of anaerobically grown cells are to be studied, special care has to be taken to prevent adaptation of the cells to aerobic surroundings during the isolation procedures, which were therefore carried out under an atmosphere of argon. Purging argon or nitrogen through the liquid was avoided since high shear forces 
resulted in premature lysis of the spheroplasts (results not shown).

When anaerobiosis could not be maintained (e.g. during centrifugation steps), cells were cooled down to $\left(0^{\circ} \mathrm{C}\right.$ under argon gas prior to further handling.

Since it has been shown that premature lysis of spheroplasts will lead to damaged mitochondria (Bruinenberg, 1985), we optimized the concentration of the osmotic stabilizer sorbitol. Measurements of the activity of (cytoplasmic) glucose-6-phosphate dehydrogenase released in the supernatant of the incubation mixture showed that $2 \mathrm{M}$ sorbitol was optimal with respect to spheroplast stability and the time required to reduce the sorbitol concentration to $0.65 \mathrm{M}$ by dialysis. The optimum concentration of Zymolyase was found to be $2000 \mathrm{U}$ in $20 \mathrm{ml}$ cell suspension $\left(100-120 \mathrm{mg}\right.$ cells $\left.\mathrm{ml}^{-1}\right)$.

Electron microscopic examination of the fractions obtained after differential centrifugation revealed that the P1-fraction mainly consisted of relatively intact mitochondria. Micrographs of the P2-fraction showed only irregular membranous structures and some vesicles (Fig. 1).

\section{Respiration of mitochondria of anaerobically grown cells}

The possible, undesirable, aerobic adaptation during handling of anaerobically grown cells would be reflected in the ability of the cells to consume oxygen. To validate the isolation procedure with respect to this adaptation, cells were incubated under conditions equivalent to those in the isolation procedure, i.e. under argon or kept at $0{ }^{\circ} \mathrm{C}$, and were subsequently checked for the maximal respiratory capacity. Zymolyase and sorbitol were not added in these control experiments. Cells incubated this way for at least $4 \mathrm{~h}$ did not acquire a higher respiratory activity. This remained constant at a low value of $10 \mu \mathrm{mol} \mathrm{min}^{-1}$ (g cell protein) ${ }^{-1}$. Approximately $50 \%$ of this activity was insensitive towards cyanide, whereas the respiration of aerobically grown cells was blocked completely by this inhibitor (Table 1). No respiration of

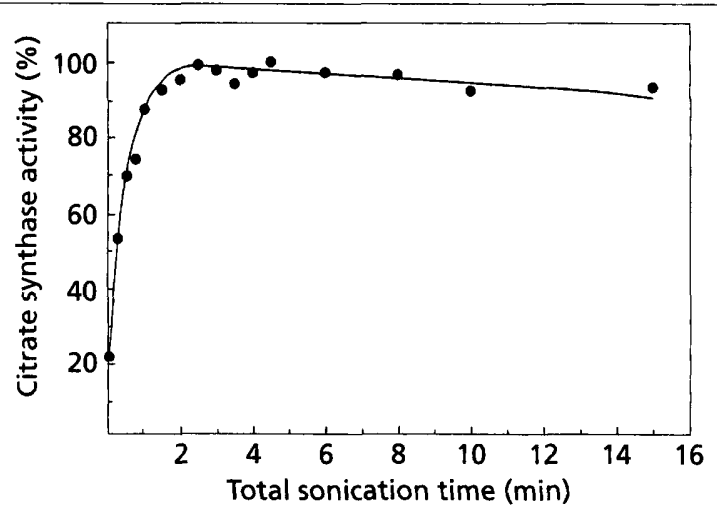

Fig. 2. The release of citrate synthase activity following ultrasonic treatment of the mitochondria isolated from anaerobically grown $S$. cerevisiae cells. Results are presented as percentage of the maximal activity after sonication.
Table 1. Maximum respiratory capacity of anaerobically and aerobically grown cells of $S$. cerevisiae, and of mitochondrial preparations of these cultures, measured in the presence and absence of $1 \mathrm{mM} \mathrm{KCN}$

\begin{tabular}{|c|c|c|c|c|}
\hline \multirow[t]{3}{*}{$\begin{array}{l}\text { Growth } \\
\text { conditions }\end{array}$} & \multicolumn{4}{|c|}{$\begin{array}{c}\mathrm{Q}_{\mathrm{O}_{2}}^{\max } \\
{\left[\mu \mathrm{mol} \mathrm{O} \mathrm{O}_{2} \min ^{-1}(\mathrm{~g} \text { protein })^{-1}\right]}\end{array}$} \\
\hline & \multicolumn{2}{|c|}{ Cells } & \multicolumn{2}{|c|}{ Mitochondria* } \\
\hline & $-\mathrm{CN}$ & $+\mathrm{CN}$ & $-\mathrm{CN}$ & $+\mathrm{CN}$ \\
\hline Aerobic & 150 & 0 & $360 \dagger$ & NT \\
\hline Anaerobic & 10 & 5 & ND & ND \\
\hline
\end{tabular}

ND, Not detectable; NT, not tested.

* In mitochondrial fractions respiration was measured with $\mathrm{NADH}$ instead of glucose as a substrate, in the presence of ADP.

† Value obtained from van Urk et al. (1989).

Table 2. Subcellular localization of citrate synthase and glucose-6-phosphate dehydrogenase in anaerobically grown S. cerevisiae

Distributions are expressed as percentage of recovered activity. This recovery was based upon the total activity in the cell free extract (fraction T), being 3 and $20 \mu \mathrm{mol} \mathrm{min}{ }^{-1}$ for citrate synthase and glucose-6-phosphate dehydrogenase, respectively. Data \pm SD are based on four independent isolations of mitochondria. P1, mitochondrial pellet fraction; P2, rest of particulate material.

\begin{tabular}{|lcc|}
\hline Fraction & $\begin{array}{c}\text { Citrate } \\
\text { synthase }\end{array}$ & $\begin{array}{c}\text { Glucose-6- } \\
\text { phosphate } \\
\text { dehydrogenase }\end{array}$ \\
\hline P1 & $79 \cdot 0 \pm 3 \cdot 3$ & $0 \cdot 8 \pm 0 \cdot 6$ \\
P2 & $10 \cdot 3 \pm 4 \cdot 1$ & $1 \cdot 0 \pm 1 \cdot 0$ \\
Total particulate & $89 \cdot 2 \pm 7 \cdot 3$ & $1 \cdot 7 \pm 1 \cdot 2$ \\
Soluble & $10 \cdot 8 \pm 7 \cdot 3$ & $98 \cdot 3 \pm 1 \cdot 2$ \\
Recovery & $87 \cdot 3 \pm 15 \cdot 6$ & $88 \cdot 4 \pm 8 \cdot 4$ \\
\hline
\end{tabular}

$\mathrm{NADH}$ was found with the mitochondria of anaerobically grown cells, indicating that no adaptation of cells to aerobic conditions had occurred during the isolation procedure.

\section{Subcellular localization of citrate synthase}

Glucose-6-phosphate dehydrogenase is a well-known cytosolic marker enzyme. As can be concluded from the distribution of the activity of this enzyme over the fractions examined (Table 2), the mitochondrial fractions isolated were hardly contaminated with cytosolic enzymes.

Citrate synthase in the mitochondrial fraction P1 exhibited latency. Only after sonication was the maximum activity reached. This is demonstrated in Fig. 2, in which the activity of the enzyme in the P1-fraction is depicted as a 


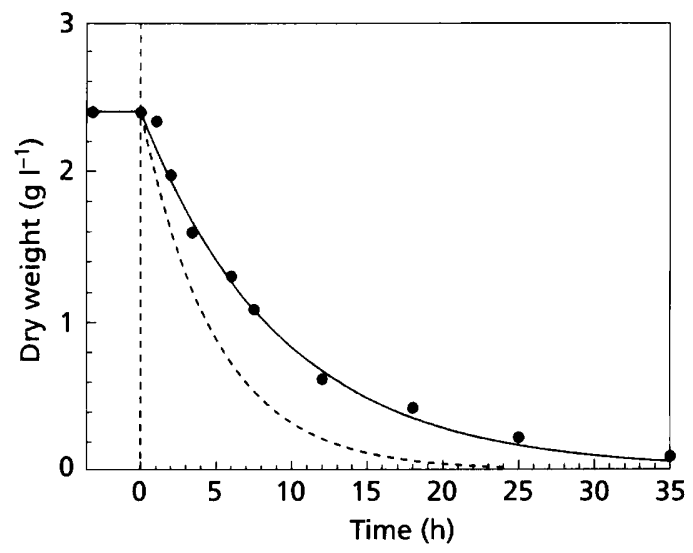

Fig. 3. Washout curve of an anaerobic continuous culture of $S$. cerevisiae [dilution rate $=0.2 \mathrm{~h}^{-1}, S_{\mathrm{R}}$ (concentration of growthlimiting nutrient in the reservoir) $=27.5 \mathrm{~g}$ glucose $1^{-1}$ ] after addition of bongkrekic acid $(5 \mu \mathrm{M})$ as a specific inhibitor of the ADP/ATP-carrier of the mitochondrial membrane at $t=0 \mathrm{~h}(\mathbf{O})$. Dashed curve refers to washout kinetics when $\mu=0$. The solid line drawn through the data points is the result of a curve fit procedure assuming that the organism is washed out according to $x=x_{0} \cdot e^{(\mu-D) t}$ where $x=$ biomass, $\mu=$ specific growth rate and $D=$ dilution rate. The data show that anaerobic growth in the presence of bongkrekic acid still proceeds with $\mu=0.1 \mathrm{~h}^{-1}$ for at least five generations.

function of the sonication time. The sonication procedure hardly damaged the enzyme, since prolonged exposure time did not significantly reduce the activity. The citrate synthase activity in the $\mathrm{P} 1$-fraction increased approximately fivefold after the sonication procedure, whereas the small amount of enzyme in the P2-fraction did not exhibit significant latency (less than 10\%).

\section{Effect of bongkrekic acid on anaerobic cultures}

Bongkrekic acid is a well-known specific inhibitor of the mitochond rial ADP/ATP-translocase of mammalian cells (beef heart and rat liver), both in intact mitochondria (Erdelt $e$ t al., 1972) and in a reconstituted system (Krämer \& Klingenberg, 1979). The same was demonstrated for the yeast mitochondrial translocase by following transport activity in proteoliposomes containing reconstituted, purified translocase of aerobically grown $S$. cerevisiae (haploid strain D 273-10B $\alpha$ ) cells with ${ }^{14} \mathrm{C}$-labelled ATP (Knirsch et al., 1989).

To investigate the in vivo role of mitochondrial translocase during anaerobic growth, inhibition of growth was followed by recording the washout kinetics of steady state cultures after the addition of bongkrekic acid. This translocase inhibitor was added at zero time to both the medium reservoir and the culture vessel to a concentration of $5 \mu \mathrm{M}$. In this way the concentration of bongkrekic acid remained constant during the washout experiment. From the washout profile after the addition of the inhibitor it can be calculated that the growth rate decreased by $50 \%$ from $0 \cdot 2$ to $0 \cdot 1 \mathrm{~h}^{-1}$ (Fig. 3). Increasing the concentration of bongkrekic acid from 5 to $50 \mu \mathrm{M}$ did not enhance the inhibitory effect (data not shown).
It has been reported (Šubík, 1972) that addition of bongkrekic acid to growing cells of $S$. cerevisiae under anaerobic conditions induced the formation of respiratory-deficient mutants. Whether a similar phenomenon would occur in our continuous culture experiment was checked by plating the samples from the washout culture on appropriate agar media, but no petite colonies were found.

\section{DISCUSSION}

\section{Anabolic functions of mitochondria during anaerobiosis}

Citrate synthase is a key enzyme of the TCA-cycle (Lowenstein, 1967; Walsh \& Koshland, 1985) catalysing the condensation of oxaloacetate and acetyl CoA to produce citrate. The TCA cycle is important under aerobic conditions, as it generates reduced coenzymes to supply the electron transport chain with substrates. The second role of the cycle is to provide the cell with anabolic precursors, such as 2-oxoglutarate, the precursor for the glutamate family of amino acids (Fig. 4). Thus, although under anaerobic conditions the first role is of no significance, the latter anabolic function is still of vital importance.

The localization of several TCA cycle enzymes under anaerobiosis has been studied for Saccharomyces carlsbergensis by Wales et al. (1980). They found that citrate synthase was almost entirely recovered in the soluble fraction, whereas with aerobically grown cells only $6 \%$ of

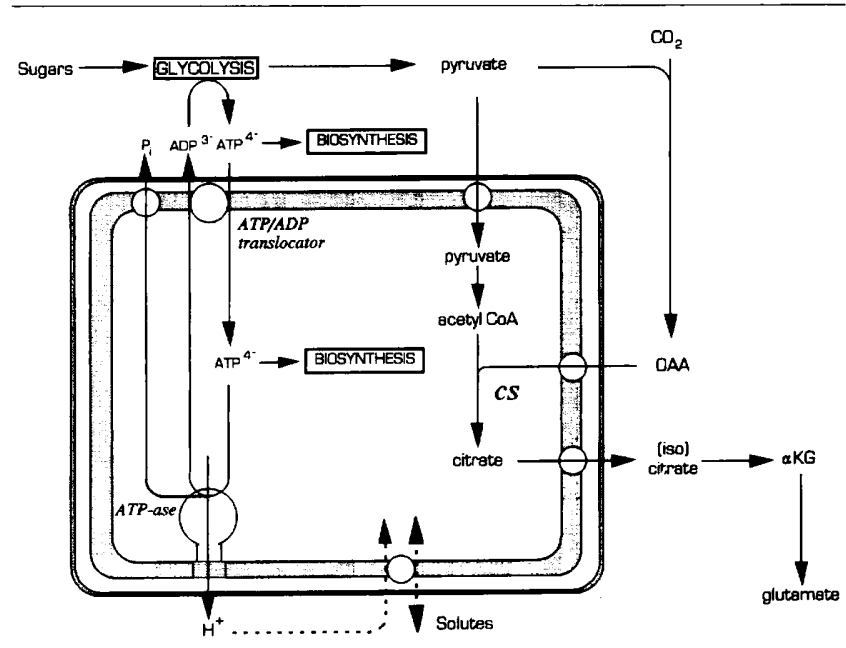

Fig. 4. Vectorial processes in mitochondria during anaerobic growth, showing the coupling of the intra- and extramitochondrial nucleotide pools by the ADP/ATPtranslocase in the inner mitochondrial membrane. Note that ATPase, when functional in anaerobic mitochondria, would build up a proton motive force by consumption of ATP, instead of dissipating the proton motive force for synthesis of ATP as occurs in aerobic cells. The proton symport (antiport) symbolizes energy-dependent transport processes across the mitochondrial membrane, for example of the metabolites shown, pyruvate, oxaloacetate (OAA), (iso)-citrate, etc. CS: citrate synthase. 
this activity was found in the supernatant. The low recovery of activity in the mitochondrial fraction of anaerobically grown cells was explained by leakage of enzyme from the more fragile (Criddle \& Schatz, 1969; Damsky, 1969) pro-mitochondria. Therefore, in this study a very gentle procedure for the isolation of the mitochondria was used.

The results, shown in Table 2 and Fig. 2, clearly show that with this procedure most of the enzyme is particulate, also under anaerobic conditions. Isoenzymes, functioning in different locations in the cell, always complicate localization studies. When, for example, yeast cells are grown on ethanol or acetate, the glyoxylate cycle is active. It has been shown that the enzymes of this route are localized in the peroxisomes. Under these conditions two different genes encoding citrate synthase are active, CIT1 encoding the mitochondrial enzyme and CIT2 the peroxisomal protein (Lewin et al., 1990). In cells grown on glucose under anaerobic conditions, however, peroxisome synthesis is repressed (Veenhuis \& Harder, 1987) and peroxisomal enzymes are not synthesized (Rogers \& Stewart, 1973).

Therefore, it seems unlikely that the particulate localization of citrate synthase is partially or totally due to contamination of the mitochondrial fraction with peroxisomes. Furthermore, since it is well-known that peroxisomes are very fragile, the observed latency of citrate synthase (Fig. 2) is also not in accordance with a peroxisomal localization of the enzyme.

\section{ATP requirements for anabolic functions of mitochondria}

The majority of the mitochondrial enzymes are encoded on the nuclear DNA and citrate synthase is no exception in this respect (Schatz \& Mason, 1974). Import of these enzymes or precursor proteins requires not only a membrane potential but also hydrolysis of matrix ATP (Eilers et al., 1987; Pfanner et al., 1987; Stuart et al., 1994). The subsequent refolding of imported proteins by mitochondrial chaperones (e.g. hsp60) requires ATP within the mitochondrial matrix (Baker \& Schatz, 1991; Stuart et al., 1994). Anabolic reactions also will depend on the supply of energy, whether this is direct as in phosphorylation reactions, or indirect as active transport processes.

Whereas under aerobic conditions ATP is produced within the mitochondria by respiration, under anaerobic conditions the energy requirement for anabolic processes necessarily implies extramitochondrial sources of energy, e.g. import of ATP into the mitochondrion.

The only possible route for mitochondrial uptake of ATP is mediated by the ADP/ATP translocator (see Fig. 4). This carrier is the most abundant protein in the mitochondrial membrane (Klingenberg, 1985) and under respiratory conditions it will export ATP and import ATP at high rates. Under these conditions, the ATP/ADP ratio in the cytosol is considerably higher than in the mitochondrial matrix. Transport therefore occurs against the chemical gradient of the substrates ATP and ADP. The driving force for this process is the membrane potential due to the fact that the exchange of $\mathrm{ATP}^{4-}$ against $\mathrm{ADP}^{3-}$ includes charge movement across the membrane. Thus, the direction of the fluxes and the relative contribution of the transport modes carrying ADP and ATP, respectively, depend on the energy state of the membrane (Krämer \& Klingenberg, 1980).

Since heterologous exchange $\left(\mathrm{ATP}^{-4}, \mathrm{ADP}^{-3}\right)$ is electrogenic, the mitochondrial import of ATP in anaerobically grown cells creates a membrane potential in the physiological direction, i.e. positive outside (see Fig. 4). On the other hand, once in the matrix, ATP may be hydrolysed by the ATPase, leading to extrusion of protons thereby generating an electrochemical proton gradient. It has to be taken into account, however, that this would also decrease further uptake of ATP by the electrogenic heterologous exchange mode of the ADP/ATP translocase to some extent.

A highly specific and effective inhibitor of the ADP/ATPtranslocator is bongkrekic acid. It has been shown that aerobic growth of respiration-deficient mutants of $S$. cerevisiae could be arrested by addition of this drug, indicating the vital importance of mitochondrial import of ATP for anabolic purposes (Šubík et al., 1972; Gbelská et al., 1983). Since anaerobic conditions of wild-type $S$. cerevisiae will lead to a similar mitochondrial energy demand as in the experiments of Subík et al. (1972) and Gbelská et al. (1983), it was expected that bongkrekic acid would be as effective in blocking growth under these conditions. Our results show that anaerobic growth was indeed inhibited, but the effect was not complete. Although our results seem contradictory to published studies on the effect of bongkrekic acid on the ADP/ATPtranslocase in respiratory-deficient mutants (Šbík et al., 1972; Gbelská et al., 1983), it should be borne in mind that so far no studies have been performed on the effect of this inhibitor on cells that were grown under strict anaerobic conditions. In this respect it is relevant that different genes ( $A A C 1, A A C 2$ and $A A C 3$ ) encode ADP/ATP-translocase in $S$. cerevisiae. $A A C 1$ and $A A C 2$ are expressed under aerobic conditions whereas $A A C 3$ is specifically expressed under anaerobic conditions (Gawaz et al., 1990; Kolarov et al., 1990). We therefore hypothesize that this third gene product is only partly inhibited by the drug and thus supports anaerobic growth in its presence.

In conclusion, the present study has provided experimental support for the contention that the mitochondria play a vital role in the anabolic metabolism of anaerobically growing cells. The term 'non-functional mitochondria', often used in the literature in the sense of 'nonrespiring mitochondria', should therefore cease to be used.

\section{ACKNOWLEDGEMENTS}

These investigations were supported by the Foundation for Biological Research (BION), which is subsidized by the Netherlands Organization for Scientific Research (NWO). We 
thank Professor Dr J. G. Kuenen and Dr J. T. Pronk for a critical reading of the manuscript.

\section{REFERENCES}

Andreasen, A. A. \& Stier, T. J. B. (1953). Anaerobic nutrition of Saccharomyces cerevisiae. I. Ergosterol requirement for growth in a defined medium. J Cell Comp Pbysiol 41, 23-26.

Andreasen, A. A. \& Stier, T. J. B. (1954). Anaerobic nutrition of $S$. cerevisiae. II. Unsaturated fatty acid requirement for growth in a defined medium. J Cell Comp Physiol 43, 271-281.

Baker, K. P. \& Schatz, G. (1991). Mitochondrial proteins essential for viability mediate protein transport into yeast mitochondria. Nature 349, 205-208.

Bruinenberg, P. M., van Dijken, J. P. \& Scheffers, W. A. (1983). An enzymic analysis of NADPH production and consumption in Candida utilis CBS 621. J Gen Microbiol 129, 965-971.

Bruinenberg, P. M., van Dijken, J. P., Kuenen, J. G. \& Scheffers, W. A. (1985). Critical parameters in the isolation of mitochondria from Candida utilis grown in continuous culture. J Gen Microbiol 131, 1035-1042.

Cartledge, T. G. \& Lloyd, D. (1972). Subcellular fractionation by zonal centrifugation of glucose-repressed anaerobically grown Saccharomyces carlsbergensis. Biochem J 127, 693-703.

Cartledge, T. G. \& Lloyd, D. (1973). Changes in enzyme activities and distributions during glucose derepression and respiratory adaptation of anaerobically grown Saccharomyces carlsbergensis. Biochem J 132, 609-621.

Cartledge, T. G., Lloyd, D., Erecińska, M. \& Chance, B. (1972). The development of the respiratory chain of Saccharomyces carlsbergensis during respiratory adaptation. Biochem $J 130,739-747$.

Chapman, C. \& Bartley, W. (1968). The kinetics of enzyme changes in yeast under conditions that cause the loss of mitochondria. Biochem J 107, 455-465.

Criddle, R. S. \& Schatz, G. (1969). Promitochondria of anaerobically grown yeast. I. Isolation and biochemical properties. Biochemistry $\mathbf{8}$, $322-334$

Damsky, C. H., Nelson, W. M. \& Claude, A. (1969). Mitochondria in anaerobically-grown, lipid-limited brewer's yeast. J Cell Biol 43, 174-179.

Eilers, M., Oppliger, W. \& Schatz, G. (1987). Both ATP and an energized inner membranc are required to import a purified precursor protein into mitochondria. EMBO J 6, 1073-1077.

Erdelt, H., Weidemann, M. J., Buchholz, M. \& Klingenberg, M. (1972). Some principal effects of bongkrekic acid on the binding of adenine nucleotides to mitochondrial membranes. Eur J Biochem 30, 107-112.

Gawaz, M., Douglas, M. G. \& Klingenberg, M. K. (1990). Structure-function studies of adenine nucleotide transport in mitochondria. II. Biochemical analysis of distinct $A A C 1$ and $A A C 2$ protein in yeast. $J$ Biol Chem 265, 14202-14208.

Gbelská, Y., Šubík, J., Svoboda, A., Goffeau, A. \& Kováč, L. (1983). Intramitochondrial ATP and cell functions: yeast cells depleted of intramitochondrial ATP lose the ability to grow and multiply. Eur $J$ Biochem 130, 281-286.

Groot, G. S. P., Kováč, L. \& Schatz, G. (1971). Promitochondria of anaerobically grown yeast. V. Energy transfer in the absence of an electron transfer chain. Proc Natl Acad Sci 68, 308-311.

Harder, W., Visser, K. \& Kuenen, J. G. (1974). Laboratory fermenter with an improved magnetic drive. Lab Pract 23, 644-645.
Jauniaux, J.-C., Urrestarazu, L. A. \& Wiame, J.-M. (1978). Arginine metabolism in Saccharomyces cerevisiae: subcellular localization of the enzymes. J Bacteriol 133, 1096-1107.

Jenkins, R. O., Cartledge, T. G. \& Lloyd, D. (1984). Respiratory adaptation of anaerobically grown Saccharomyces uvarum: changes in distribution of enzymes. J Gen Microbiol 130, 2809-2816.

Jensen, R. E. \& Yaffe, M. P. (1988). Input of proteins into yeast mitochondria: the nuclear $M A S 2$ gene encodes a component of the processing protease that is homologous to the $M A S 1$-encoded subunit. EMBO J 7, 3863-3871.

Klingenberg, M. (1985). The ADP/ATP carrier in mitochondrial membranes. In The Enzymes of Biological Membranes, Vol. 4, pp. 511-553. Edited by A. N. Martonosi. New York: Plenum Press.

Knirsch, M., Gawaz, P. \& Klingenberg, M. (1989). The isolation and reconstitution of the ADP/ATP carrier from wild-type Saccharomyces cerevisiae. Identification of primarily one type (AAC2). FEBS Lett 244, 427-432.

Kolarov, J., Kolarova, N. \& Nelson, N. (1990). A third ADP/ATP translocator gene in yeast. J Biol Chem 265, 12711-12716.

Krämer, R. \& Klingenberg, M. (1979). Reconstitution of adenine nucleotide transport from beef heart mitochondria. Biochemistry 18 , 4209--4215.

Krämer, R. \& Klingenberg, M. (1980). Modulation of the reconstituted adenine nucleotide exchange by membrane potential. Biochemistry 19, 556-560.

Lewin, A. S., Hines, V. \& Small, G. M. (1990). Citrate synthase encoded by the CIT2 gene of Saccharomyces cerevisiae is peroxisomal. Mol Cell Biol 10, 1399-1405.

Linnane, A. W. (1965). Aspects of the biosynthesis of the mitochondria of Saccharomyces cerevisiae. In Oxidases and Related Redox Systems, pp. 1102-1128. Edited by T. E. King, H. S. Mason \& M. Morrison. New York: John Wiley \& Sons.

Lowenstein, J. M. (1967). The tricarboxylic acid cycle. In Metabolic Pathways, Vol. 1, pp. 146-254. Edited by D. M. Greenberg. New York: Academic Press.

Pfanner, N., Tropschug, M. \& Neupert, W. (1987). Mitochondrial protein import : nucleoside triphosphates are involved in conferring import-competence to precursors. Cell 49, 19-27.

Rogers, P. J. \& Stewart, P. R. (1973). Mitochondrial and peroxisomal contributions to the energy metabolism of Saccharomyces cerevisiae in continuous culture. J Gen Microbiol 79, 205-217.

Ryan, E. D. \& Kohlhaw, G. B. (1974). Subcellular localization of isoleucine-valine biosynthetic enzymes in yeast. $J$ Bacteriol 120, 631-637.

Schatz, G. \& Mason, T. (1974). The biosynthesis of mitochondrial proteins. Annu Rev Biochem 43, 51-87.

Shimizu, I., Nagai, J., Hatanaka, H. \& Katsuki, H. (1973). Mevalonate synthesis in the mitochondria of yeast. Biochim Biopbys Acta 296, 310-320.

Stuart, R. A., Gruhler, A., Van der Klei, I., Guiard, B., Koll, H. \& Neupert, W. (1994). The requirement of matrix ATP for the import of precursor proteins into the mitochondrial matrix and intermembrane space. Eur J Biochem 220, 9-18.

Šubík, J., Kolarov, J. \& Kováč, L. K. (1972). Obligatory requirement of intramitochondrial ATP for normal functioning of the eukaryotic cell. Biochem Biophys Res Commun 49, 192-198.

van Urk, H., Bruinenberg, P. M., Veenhuis, M., Scheffers, W. A. \& van Dijken, J. P. (1989). Respiratory capacities of mitochondria of Saccharomyces cerevisiae CBS 8066 and Candida utilis CBS 621 grown under glucose limitation. Antonie Leewwenboek 56, 211-220.

Veenhuis, M. \& Harder, W. (1987). Metabolic significance and 
biogenesis of microbodies in yeasts. In Peroxisomes in Biology and Medicine, pp. 436-458. Edited by H. D. Fahimi \& H. Sies. Berlin: Springer Verlag.

Verduyn, C., Postma, E., Scheffers, W. A. \& van Dijken, J. P. (1990). Energetics of Saccharomyces cerevisiae in anaerobic glucose-liraited chemostat cultures. J Gen Microbiol 136, 405-412.

Verduyn, C., Postma, E., Scheffers, W. A. \& van Dijken, J.P. (1992). Effect of benzoic acid on metabolic fluxes in yeasts: a continuous culture study on the regulation of respiration and alcoholic fermentation. Yeast 8, 501-517.

Wales, D. S., Cartledge, T. G. \& Lloyd, D. (1980). Effects of glucose repression and anaerobiosis on the activities and subcellular distribution of tricarboxylic acid cycle and associated enzymes in Saccharomyces carlsbergensis. J Gen Microbiol 116, 93-98.

Wallace, P. G. \& Linnane, A. W. (1964). Oxygen-induced synthesis of yeast mitochondria. Nature 201, 1191-1194.

Walsh, K. \& Koshland, D. E., Jr (1985). Characterization of ratecontrolling steps in vivo by the use of an adjustable expression vector. Proc Natl Acad Sci US A 82, 3577-3581.

Received 7 June 1994; revised 18 July 1994; accepted 22 July 1994. 